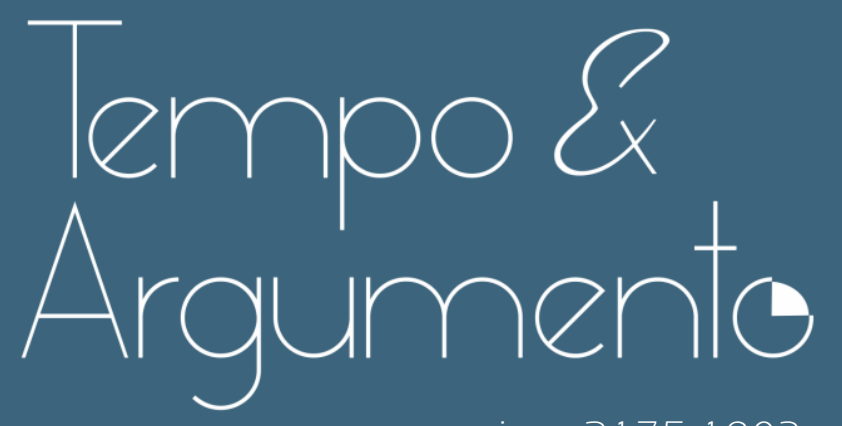

e-issn 2175-1803

Reflexões acerca do conceito de populismo: da teoria clássica às contribuições de Ernesto Laclau

- Alessandro Batistella

Doutor em História pela Universidade Federal do Rio Grande do Sul (UFRGS).

Professor na Universidade de Passo Fundo (UPF).

Passo Fundo, RS - BRASIL

lattes.cnpq.br/9628028081184238

alessandrobatistella@yahoo.com.br

(D) orcid.org/0000-0003-4606-8249

Para citar este artigo:

BATISTELLA, Alessandro. Reflexões acerca do conceito de populismo: da teoria clássica às contribuiç̧ões de Ernesto Laclau. Tempo e Argumento, Florianópolis, v. 12, n. 29, e0204, jan./abr. 2020

do) http://dx.doi.org/10.5965/2175180312292020e0204

Recebido: 06/03/2018

Aprovado: 24/05/2019 


\title{
Reflexões acerca do conceito de populismo: da teoria clássica às contribuições de Ernesto Laclau' ${ }^{1}$
}

\begin{abstract}
Resumo
O presente artigo visa a refletir sobre o conceito de populismo, que, no Brasil, vem sendo objeto de amplos debates nas últimas décadas. Dessa forma, em um primeiro momento, a análise será focada, de forma sucinta, na trajetória do referido conceito no Brasil, verificando como a teoria da modernização, os estudos do Grupo de Itatiaia e os trabalhos de Francisco Weffort e Octávio Ianni contribuíram para a construção de uma teoria, que denominaremos como clássica, e para a consolidação do conceito de populismo no país. Em um segundo momento, refletir-se-á sobre como as contribuições de Edward P. Thompson, a nova história do trabalho e a história cultural influenciaram uma nova geração de historiadores a fomentarem uma série de novos estudos que criticaram algumas das premissas que sustentam a teoria clássica do populismo. Posteriormente, o foco serão as reflexões de Ernesto Laclau sobre o conceito de populismo, reflexões estas que são ainda pouco difundidas no Brasil, mas que encontram repercussão na América Latina e Europa, permitindo-nos repensar teoricamente o conceito.
\end{abstract}

Palavras-chave: Populismo. Ernesto Laclau. Neopopulismo.

\section{Reflections on the concept of populism: from the classical theory to the contributions of Ernesto Laclau}

\begin{abstract}
This paper aims to reflect on the concept of populism, which in Brazil has been the subject of extensive debates in most recent decades. Thus, in a first moment, the analysis will be focused, in a succinct way, on the trajectory of this concept in Brazil by verifying how the theory of modernization, the studies of the Itatiaia Group, and the works of Francisco Weffort and Octavio lanni contributed to the construction of a theory - referred in this paper as "classical" - and for the consolidation of the concept of populism in the country. Second, this paper will reflect on how the contributions of Edward P. Thompson, the new history of work, and cultural history have influenced a new generation of historians to foster a series of new studies that have criticized some of the premises that support the classical theory of populism. Later, this paper focus will be the reflections of the Ernesto Laclau on the concept of populism, reflections that are still little diffused in Brazil, but that have repercussion in Latin America and Europe, allowing us to theoretically rethink the concept.
\end{abstract}

Keywords: Populism. Ernesto Laclau. Neo populism. 


\section{Considerações Iniciais}

Desde o final do século XX e início do século XXI estamos assistindo a emergência de líderes, partidos, ideologias, discursos e movimentos políticos que são denominados como "neopopulistas" ou como "populismos de direita" (como, por exemplo, a Frente Nacional de Jean-Marie Le Pen e sua filha Marine Le Pen, na França; Donald Trump, nos Estados Unidos, Jair Bolsonaro, no Brasil; entre outros) ou "populismos de esquerda" (como Hugo Chávez, na Venezuela; Evo Morales, na Bolívia; Luiz Inácio Lula da Silva, no Brasil; entre outros).

Desse modo, o presente artigo pretende refletir sobre o conceito de populismo, um conceito polêmico, cujas definições, conforme observam, por exemplo, Norberto Bobbio, Nicola Matteucci e Gianfranco Pasquino (1995, p. $980-$ 981) e Francisco Panizza (2009, p. 9) são imprecisas e ambíguas, além de o termo também ser utilizado genericamente para denominar fenômenos históricos muito diferentes. Especificamente no Brasil, nas últimas décadas, o conceito de populismo vem sendo objeto de debates e críticas realizadas, sobretudo, por historiadores, cientistas políticos e sociólogos. Assim, pretende-se, ao longo do presente artigo, analisar alguns dos principais argumentos que envolvem esse debate, além de se refletir acerca da operacionalidade ou não desse conceito.

Em um primeiro momento, a análise será focada, de uma forma sucinta, na trajetória do referido conceito no Brasil, verificando como a teoria da modernização, os estudos do Grupo de Itatiaia e os trabalhos de Francisco Weffort e Octávio lanni contribuíram para a construção de uma teoria, que denominaremos como clássica, e para a consolidação do conceito de populismo no país.

Em um segundo momento, refletir-se-á sobre como as contribuições de Edward P. Thompson, a nova história do trabalho e a história cultural influenciaram uma nova geração de historiadores a fomentarem uma série de novos estudos que criticaram algumas das premissas que sustentam a teoria clássica do populismo. 
Posteriormente, o foco serão as reflexões do cientista político argentino Ernesto Laclau² (1935-2014) sobre o conceito de populismo, reflexões estas que são ainda pouco difundidas no Brasil, mas que encontram repercussão na América Latina e Europa, permitindo-nos repensar teoricamente o conceito.

\section{Breve trajetória de um conceito}

Conforme Jorge Ferreira (2001, p. 64), nos anos 1950 e 1960, a teoria da modernização teve um grande impacto sobre a construção do conceito de populismo. Nesse sentido, dois importantes intelectuais argentinos, os sociólogos Gino Germani e Torcuato di Tella, influenciados pela teoria da modernização, definiram o populismo como um período de transição entre a sociedade tradicional (rural e agrária) e a sociedade moderna (urbana e industrial) - uma espécie de epifenômeno de um estágio específico do desenvolvimento econômico -, período esse em que as populações rurais, "inexperientes politicamente e acostumadas às relações clientelistas", se deslocavam do campo

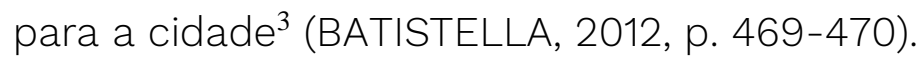

As ideias de Germani e di Tella influenciaram as primeiras formulações do populismo no Brasil, realizadas por um grupo de intelectuais que ficaram conhecidos como Grupo de Itatiaia ${ }^{4}$, que, a partir da teoria da modernização, assim definiram o populismo: Em primeiro lugar, o populismo é uma política de massas, vale dizer, é um fenômeno vinculado à proletarização dos trabalhadores na sociedade complexa moderna, sendo indicativo de que tais trabalhadores não adquiriram consciência e sentimento de classe: não estão organizados e participando da política como classe. As massas, interpretadas pelo populismo, são originárias do proletariado, mas dele se distinguem por sua

\footnotetext{
${ }^{2}$ Ernesto Laclau nasceu em 1935 na Argentina, Licenciando-se em História pela Universidade de Buenos Aires. Na década de 1970 se radicou na Inglaterra, onde realizou o seu doutorado na Universidade de Essex. Foi professor da Universidade de Essex, onde dirigiu o Programa de Ideologia e Análise do Discurso.

${ }^{3}$ Conforme essa perspectiva, o conceito de populismo foi transformado em uma teoria universal, ou seja, o populismo se transformou em uma fase intermediária do desenvolvimento capitalista. Dessa forma, houve populismo nos Estados Unidos, na Rússia, na Europa e na América Latina (IANNI, 1989).

${ }^{4}$ Segundo Angela de Castro Gomes (2001, p. 22-23), o Grupo de Itatiaia era formado por um grupo de intelectuais que, a partir de agosto de 1952, patrocinados pelo Ministério da Agricultura, realizavam reuniões periódicas em Itatiaia (entre o Rio de Janeiro e São Paulo) visando a discutir os problemas políticos, econômicos e sociais relacionados ao desenvolvimento do país. Em 1953, o Grupo de Itatiaia criou o Instituto Brasileiro de Economia, Sociologia e Política (IBESP) e publicou os Cadernos do nosso tempo. Entre os intelectuais do Grupo de Itatiaia, destacaram-se os sociólogos Hélio Jaguaribe e Alberto Guerreiro Ramos.
} 
inconsciência das relações de espoliação sob as quais vivem. Só a superação desta condição de massificação permitiria a libertação do populismo ou a aquisição da verdadeira consciência de classe. [...].

Em segundo lugar, o populismo está igualmente associado a uma certa conformação da classe dirigente, que perdeu sua representatividade e poder de exemplaridade, deixando de criar os valores e os estilos de vida orientadores de toda a sociedade. Em crise e sem condições de dirigir com segurança o Estado, a classe dominante precisa conquistar o apoio político das massas emergentes. Finalmente satisfeitas estas duas condições mais amplas, é preciso um terceiro elemento para completar o ciclo: o surgimento do líder populista, do homem carregado de carisma, capaz de mobilizar as massas e empolgar o poder. (GOMES, 2001, p. 24-25).

Nesse sentido, Angela de Castro Gomes (2001, p. 25-26) observa que há três variáveis efetuadas na construção do conceito de populismo: um proletariado sem consciência de classe; uma classe dirigente em crise de hegemonia; um líder carismático.

A partir da década de 1960, dando continuidade a essa linha interpretativa, as reflexões sobre o populismo ganharam destaque acadêmico com os trabalhos de Francisco Weffort e Octávio Ianni. Em O populismo na política brasileira ${ }^{5}$, Weffort interpreta que o populismo, surgido após um longo processo de transformação da sociedade brasileira desde 1930, se manifestará como um estilo de governo e como uma política de massas, utilizando o tripé "repressão, manipulação e satisfação" para explicar o sucesso do populismo no Brasil. Desse modo, a conjugação da repressão estatal com a manipulação política das massas e a satisfação dos trabalhadores ao verem algumas de suas demandas atendidas deram origem ao "pacto populista"6 (BATISTELLA, 2012, p. 471).

Octávio lanni, por sua vez, procurando analisar a história política brasileira e as razões do golpe civil-militar de 1964, publicou, em 1968, o colapso do populismo no Brasil. Nessa obra, Ianni vai delimitar temporalmente o populismo entre os anos de 1945 e 1964, período denominado de "democracia populista",

\footnotetext{
5 o populismo na política brasileira, publicado em 1978, aglutina (com revisões) artigos publicados pelo autor na década de 1960 (ver primeira parte do livro) e capítulos da sua tese de doutoramento apresentada à USP, em 1968 (ver a segunda parte do livro).

${ }^{6}$ Segundo esse pacto, "os trabalhadores, a partir de cálculos utilitários sobre suas perdas e ganhos, trocaram os benefícios do acesso aos direitos sociais pela submissão política" (FERREIRA, 1997, p. 15).
} 
interpretando o golpe civil-militar de 1964 como resultado do esgotamento do populismo no Brasil, isto é, o colapso de um modelo de desenvolvimento econômico característico de um período de transição (de uma sociedade de base agrária para uma sociedade urbana e industrial) conduzido por um Estado intervencionista e por líderes carismáticos, que buscam legitimar-se através da política de massas. Ainda segundo lanni, essa política de massas seria uma forma de organizar, controlar e utilizar a força política dos trabalhadores, que, em virtude da sua origem rural, seu atraso cultural e sua inexperiência política, estavam destituídos de uma consciência de classe, sendo facilmente galvanizados e instrumentalizados pelas lideranças carismáticas.

Aliás, convém salientar que além da teoria da modernização, Weffort e lanni também iriam utilizar (e ao mesmo tempo contribuir) outras reflexões que estavam surgindo na década de 1960: os primeiros estudos sobre o movimento operário e sindical brasileiro, realizados por intelectuais como Juarez Brandão Lopes, Leôncio Martins Rodrigues, Azis Simão e José Albertino Rodrigues, entre outros. Em geral, os trabalhos desses autores, embora possuam particularidades, apresentam uma espécie de "síntese geral": enaltecem os anos 1910 como os anos dourados do anarquismo e dos movimentos reivindicatórias da Primeira República; atribuem a retração dos movimentos contestatórios dos anos 1920 ao incipiente êxodo rural, uma vez que os trabalhadores rurais não tinham experiências de luta; e caracterizavam o sindicalismo do período pós-1930 como burocrático e acomodado, perdendo sua autonomia e seu ímpeto revolucionário (BATISTELLA, 2012, p. 472).

Em geral, os trabalhos sobre o populismo de lanni e Weffort e os primeiros estudos sobre o movimento operário e sindical brasileiro foram produzidos em um contexto pós-golpe de 1964 e durante os anos da ditadura militar, o que levou esses intelectuais a refletirem sobre as razões do golpe. E foi nessa conjuntura que surgiram outras teorias, como a do "desvio" e do "cupulismo".

A teoria do "desvio" baseia-se em uma visão teleológica do marxismo de que a classe operária, ao tomar consciência de classe, teria um caminho natural a seguir (a revolução do proletariado). No entanto, a política populista - por meio da repressão, da manipulação e da cooptação - teria incapacitado os 
trabalhadores a qualquer iniciativa autônoma e de criarem consciência de classe (BATISTELLA, 2012, p. 472).

Por sua vez, na teoria do cupulismo "os trabalhadores seriam reféns da política ditada pelas suas lideranças" (COSTA, H., 1999, p. 90), que agiam sem consultar os trabalhadores ${ }^{7}$. Dessa forma, o cupulismo seria responsável pelo êxito da política populista no seio do movimento operário, uma vez que os operários estavam nas mãos de lideranças pelegas ou nas mãos de lideranças comunistas, que cometiam uma série de equívocos e erros estratégicos ${ }^{8}$ (como, por exemplo, as alianças com sindicalistas petebistas).

Em suma, o populismo - que teria desviado a classe operária - e o cupulismo tornaram-se fatores explicativos para a suposta fraqueza do movimento operário diante do golpe civil-militar de 1964, que foi deflagrado sem maiores resistências (BATISTELLA, 2012, p. 473).

Dessa forma, paulatinamente difundiu-se uma vertente explicativa que passou a desmerecer a história social e política brasileira entre os anos de 1930 e 1964, sobretudo o período entre 1945 e 1964, que passou a ser denominado pejorativamente como o "tempo da democracia populista" (ou da "república populista") e do "sindicalismo populista", caracterizado como o período dos políticos populistas, demagógicos e carismáticos, do sindicalismo pelego, dos trabalhadores domesticados e sem autonomia, vitimados por uma modernização incompleta e manipulados por um Estado paternalista e coercitivo (especialmente no Estado Novo) (BATISTELLA, 2012, p. 473).

Nessa perspectiva, o populismo era interpretado como

[...] uma relação pessoal entre um líder e um conglomerado de indivíduos, relação essa explicada através do recurso à ideia de demagogia, nem sempre claramente definida. Segundo essa concepção, o líder populista não aparece como um verdadeiro

\footnotetext{
Conforme Hélio da Costa (1999, p. 90), o sindicalismo cupulista pode ser caracterizado como: "ausência de organização nos locais de trabalho em contraponto ao esforço destinado à construção de estruturas paralelas fortemente verticalizadas; distância em relação às reivindicações ligadas às condições de vida dos trabalhadores; recusa em romper o atrelamento dos sindicatos ao Estado".

${ }^{8}$ Nesse sentido, Francisco Martinho (1996) lembra que as análises de Francisco Weffort são duras com o PCB, inclusive o responsabilizando pelo predomínio da estrutura corporativa no período de 1945 a 1964.
} 
político, mas, sobretudo, como um aproveitador da ignorância popular, e as massas, na sua irracionalidade, não constituem fundamento para qualquer tipo de política. O populismo, desse ponto de vista, seria, pois, um fenômeno pré-político ou parapolítico. (DEBERT, 1979, p. 1).

Ademais, seguindo uma perspectiva linear, progressiva e até mesmo teleológica da história, o período populista era um período datado, transitório, um estágio do processo do desenvolvimento capitalista (caracterizado pela proletarização dos camponeses, pela crise de hegemonia das antigas oligarquias agrárias, pelo pacto entre as diversas classes sociais e pelo fascínio das massas aos líderes carismáticos) (BATISTELLA, 2012, p. 473).

Baseando-se nessas premissas, o Novo Sindicalismo, que emergiu no cenário social e político brasileiro no final da década de 1970, procurou cunhar a sua auto identidade como oposição ao "velho" sindicalismo pelego do período 1930-1964 - surgindo, assim, um "novo" sindicalismo, que sepultaria o colaboracionismo e o cupulismo e assumiria a defesa dos interesses dos trabalhadores ${ }^{9}$ (BATISTELLA, 2012, p. 474).

Portanto, a teoria clássica do populismo apresenta os trabalhadores brasileiros do período 1930-1964 como passivos, destituídos de experiência e consciência de classe (ou com as suas experiências atreladas ao populismo), facilmente manipulados e cooptados por um Estado paternalista e por líderes carismáticos e demagógicos, que os teriam desviado de seu caminho histórico natural. Diante desses pressupostos, observou Jorge Ferreira que

[...] a história da classe trabalhadora a partir de 1930 reduz-se a uma espécie de "conspiração" das classes dominantes sempre criadoras de dispositivos ideológicos, mecanismos eficientes de controle social, meios habilíssimos de propaganda política, instrumentos sutis de doutrinação das mentes, entre outros meios, para manipular, dominar e desvirtuar os trabalhadores de seus "reais e verdadeiros" interesses. (FERREIRA, 1997, p. 14).

Além disso, a teoria clássica do populismo carece de precisão, uma vez que aglutina projetos políticos (nacional-desenvolvimentismo e liberalismo, por

\footnotetext{
Sobre os limites do discurso e da auto-imagem cunhada pelo Novo Sindicalismo, ver a coletânea: FORTES, Alexandre; NEGRO, Antonio Luigi; SILVA, Fernando Teixeira da; COSTA, Hélio da; FONTES, Paulo (Orgs.). Na luta por direitos: estudos recentes em história social do trabalho. Campinas: Unicamp, 1999.
} 
exemplo), lideranças (Getúlio Vargas, João Goulart, Adhemar de Barros, Jânio Quadros, Leonel Brizola, entre outros) e partidos políticos tão díspares e até mesmo antagônicos entre si. Dessa forma, o período da experiência democrática que vivenciou o país entre 1945 e 1964 - caracterizada pela afirmação dos partidos políticos, pelo crescimento eleitoral, pela ideologia nacionaldesenvolvimentista, pela ascensão e consolidação de movimentos sociais urbanos e rurais e dos trabalhadores como importantes atores políticos, etc. acaba sendo simplificada na ideia de que políticos personalistas e demagogos facilmente manipulavam e controlavam um povo apático e alienado (BATISTELLA, 2012, p. 474).

Contudo, a partir de meados da década de 1980 e, sobretudo, a partir da década de 1990, surgiram novos estudos sobre o movimento operário e sindical brasileiro, sobre o trabalhismo e sobre a história política do país, entre outros, que iriam criticar algumas das premissas da teoria clássica do populismo.

\section{O colapso do conceito de populismo?}

A partir de meados da década de 1980, a influência de Edward P. Thompson promoveu uma renovação nos estudos sobre o movimento operário e sindical no Brasil. Afastando-se do viés estruturalista e aproximando-se da antropologia, a "history from bellow" (história vista de baixo) thompsoniana "colocou as noções de experiência e cultura no cerne das análises sobre a ação social". Dessa forma, "o desenvolvimento da problemática tendeu rapidamente a ultrapassar o interesse inicial no ativismo operário, para concentrar-se na compreensão da experiência das pessoas comuns, no passado, e de suas reações a esta própria experiência" (CASTRO, 1997, p. 51).

Referindo-se à experiência, Edward P. Thompson diz que

Os homens e mulheres também retornam como sujeitos, dentro deste termo [experiência] - não como sujeitos autônomos, "indivíduos livres", mas como pessoas que experimentam suas situações e relações produtivas determinadas como necessidades e interesses e como antagonismos, e em seguida "tratam" essa experiência em sua consciência e sua cultura [...] das mais 
complexas maneiras [...] e em seguida [...] agem, por sua vez, sobre sua situação determinada. (THOMPSON, 1981, p. 182).

Emília Viotti da Costa (2001, p. 20-21) atesta a influência thompsoniana na nova história do trabalho latino-americana: houve uma passagem do estudo das lideranças para o estudo da base; do estudo dos sindicatos e partidos políticos para o estudo da cultura dos trabalhadores; do estudo do movimento organizado dos trabalhadores para o estudo da grande maioria dos trabalhadores que nunca se filiaram a um sindicato, entre outros. Em outras palavras, "enquanto no passado os historiadores falavam de 'estruturas', agora falam de 'experiência'" (BATISTELLA, 2012, p. 475).

No Brasil, um dos trabalhos pioneiros foi $A$ invenção do trabalhismo, de Angela de Castro Gomes, publicado em $1988^{10}$. Segundo a autora, seu objetivo era

[...] recusar radicalmente as idéias de uma classe trabalhadora passiva e sem "uma verdadeira consciência", sendo, por isso, manipulada e enganada por políticos cínicos e inescrupulosos que, sem bases partidárias, fundavam sua representatividade em prestígio pessoal. Por outro lado, queria enfatizar as idéias de uma classe trabalhadora sujeito de sua história, que se relacionava com políticos cujas bases de atuação excediam o personalismo e se combinavam com instituições partidárias e sindicais, e também com políticas públicas de alcance social, em parte implementadas. Enfim, queria destacar a existência de uma relação dinâmica entre Estado e classe trabalhadora, em que as idéias e práticas nelas contidas são permanentemente reinventadas através do tempo. (GOMES, 2002, p. 59).

Nesse sentido, Emília Viotti da Costa (2001, p. 29-30) ressalta que a nova história do trabalho "questionou a imagem tradicional de uma população rural passiva e reavaliou as relações entre o trabalho urbano e rural", descrevendo "os migrantes rurais não como vítimas da manipulação e de líderes populistas carismáticos, e sim como atores históricos conscientes e autônomos, capazes de fazer opções racionais".

Observa Emília Viotti da Costa (2001, p. 30-31), que a nova história do trabalho demonstra como "os trabalhadores se apropriam dos símbolos da elite e thes dão novos significados, empurrando o peronismo, o somozismo e o

\footnotetext{
10 Ver: GOMES, Angela de Castro. A invenção do trabalhismo. Rio de Janeiro: IUPERJ, 1988.
} 
varguismo muito além dos limites propostos pelas intenções dos líderes”. Nesse sentido, não podemos esquecer a contribuição da história cultural, particularmente o conceito de circularidade cultural de Carlo Ginzburg, que demonstra que as ideias não são produzidas apenas pelas elites e impostas de cima para baixo. Assim, mais uma premissa da teoria clássica do populismo é criticada: a de que um Estado, por meio da doutrinação e propaganda política, inculcava valores, crenças e ideias nas mentes das pessoas (BATISTELLA, 2012, p. 476-477).

Portanto, por meio das novas perspectivas abertas pela influência thompsoniana e pela história cultural, a nova história do trabalho relativizou e criticou alguns dos pilares que sustentam a teoria clássica do populismo - como, por exemplo, o viés estruturalista presente na teoria da modernização, a ideia da manipulação de uma massa passiva e sem consciência, a amplificação da propaganda política nas mentes das massas, etc. (BATISTELLA, 2012, p. 477).

No entanto, nos discursos político-partidários, na mídia, em alguns círculos intelectuais e no senso comum da população, essa versão clássica ainda está fortemente consolidada e parece imune às críticas. Diante dessa constatação, Angela de Castro Gomes (2002, p. 63) considera o populismo como "uma das construções míticas mais importantes de nosso imaginário social", um verdadeiro "gato de sete vidas".

Por sua vez, nos círculos acadêmicos, o debate envolvendo o conceito de populismo constitui-se em um dos mais complexos e controversos. Atualmente, além das correntes que defendem e utilizam as premissas da teoria clássica do populismo, há outros dois grupos: os que defendem o total abandono do conceito; e os que defendem a sua utilização, porém, sem ancorar-se nas premissas clássicas da sua teoria.

O grupo que defende o abandono do conceito de "populismo" (capitaneado, sobretudo, por historiadores como Angela de Castro Gomes, Jorge Ferreira e Daniel Aarão Reis Filho) destaca, entre outras coisas, a sua imprecisão conceitual e a sua conotação pejorativa e desqualificadora. Para Jorge Ferreira, 
[...] O populista é o adversário, o concorrente, o desafeto. O populista é o Outro. Trata-se de uma questão eminentemente política e, muito possivelmente, político-partidária, que poderia ser enunciada da seguinte maneira: o meu candidato, o meu partido, a minha proposta política não são populistas, mas o teu candidato, o teu partido e a tua proposta política, estes, sim, são populistas. Populista é sempre o Outro, nunca o Mesmo. (FERREIRA, 2001, p. 124).

Por sua vez, Angela de Castro Gomes, em A invenção do trabalhismo, salienta que procurou rejeitar o uso do conceito de "populismo" e propôs a idéia do "pacto trabalhista" para refletir acerca das relações entre Estado e classe trabalhadora. Segundo a autora, esse pacto efetuado pelo povo e Getúlio Vargas começou a se delinear a partir de 1942, com o esforço do governo em estreitar os laços com os trabalhadores e em legitimar o Estado e o próprio Vargas como responsáveis pelas leis sociais (por meio da "ideologia da outorga") e como protetores dos trabalhadores. Ainda segundo a autora:

A proposta realizada [...] assinala que o discurso trabalhista, articulado em início dos anos 1940, apropria e ressignifica o discurso operário construído, de forma lenta e diversificada, nos anos da Primeira República. Os benefícios materiais "oferecidos" e implementados [...] serão "recebidos" e interpretados pela classe trabalhadora, que os apreenderá e os manejará segundo os termos de suas possibilidades e vivências. O pacto trabalhista, pensado ao longo do tempo, tem nele, de modo integrado, mas não redutível, tanto a palavra e a ação do Estado (que, sem dúvida, teve o privilégio de desencadeá-lo), quanto a palavra e a ação da classe trabalhadora, ressaltando-se que nenhum dos dois atores é uma totalidade harmônica, mantendo-se num processo de permanente re-construção. (GOMES, 2001, p. 48).

O pacto trabalhista proposto por Angela de Castro Gomes difere-se do "pacto populista", uma vez que constituía um "pacto de reciprocidade", de "reconhecimento de valores", de "gratidão" e de "retribuição" (que ganhou força em virtude da construção simbólica de Vargas no pós-1940), enquanto o "pacto populista" é apenas baseado em trocas utilitárias, em que ganhos materiais eram trocados por obediência política.

Em suma, para Angela de Castro Gomes (2002, p. 67) o populismo é um mito político marcado pela "desesperança e o ceticismo", que "rebaixa a sociedade brasileira", enquanto o trabalhismo pode ser definido como uma 
tradição política (que, inclusive precedeu o próprio conceito de populismo). Conforme a autora:

O trabalhismo deve ser entendido como se constituindo de um conjunto de idéias, valores, símbolos, rituais e vocabulários que passa a se solidificar especificamente a partir da década de 1940. Desde então, começa a circular num circuito que comunica setores de elite com setores populares, ganhando sentidos específicos em cada um desses pólos, em diferentes conjunturas políticas. É evidente que, como ideologia e projeto políticos, o trabalhismo lança raízes na experiência do movimento operário e sindical da Primeira República, no sentido thompsoniano. Ou seja, se a tradição é inventada no pós-1930, não o é de forma fortuita, arbitrária e a partir do nada. Seu poder de significação e mobilização (a "comunidade de sentidos" que logrou estabelecer) veio justamente da releitura que as elites políticas do pós-1930 realizaram do que ocorreu no terreno das lutas dos trabalhadores, antes de 1930. [...] Ademais, pode-se verificar que, como tradição, o trabalhismo será apropriado e reinventado no pós-1945, tanto por setores sindicais e populares, quanto por setores das elites políticas, especialmente as dos partidos trabalhistas, com destaque para as do PTB. (GOMES, 2002, p. 67-68).

Compartilhando dessa ideia, Daniel Aarão Reis Filho (2001, p. 345-346) argumentará que a tradição trabalhista (caracterizada pelas lutas sociais, pela defesa das bandeiras reformistas e nacionalistas, pela crescente participação das massas na política nacional, pelo estilo de fazer política de lideranças carismáticas, etc.) fora rebatizada de populismo pelos conservadores com o intuito de destruí-la e estigmatizá-la (BATISTELLA, 2012, p. 479).

Por outro lado, há uma corrente de historiadores que não descarta a utilização do conceito de populismo, embora desconsiderem algumas premissas da sua teoria clássica, como manipulação, passividade dos trabalhadores, falta de consciência de classe, etc. Dentre esses autores, podemos citar historiadores ligados à nova história do trabalho, como John French, Paulo Fontes, Hélio da Costa, Fernando Teixeira da Silva, Alexandre Fortes, entre outros (BATISTELLA, 2012, p. 479).

Refratando a argumentação de Jorge Ferreira sobre a incompatibilidade entre as ideias thompsonianas e o conceito de populismo, Alexandre Fortes argumentará que, para Thompson, o populismo 
[...] designa a ênfase no protagonismo popular, uma perspectiva democrática radical (mas não ainda socialista) que distinguiu o movimento pela reforma política na Inglaterra em função da composição de sua base social e de sua trajetória histórica, ambas peculiares no período. Essa abordagem levanta a possibilidade de dissociarmos o conceito de "populismo" da idéia de "manipulação" ou "desvio de uma consciência. política ideal". (FORTES, 2010, p. 190).

Fernando Teixeira da Silva e Hélio da Costa identificam nas análises de Thompson sobre paternalismo uma chave para repensar o populismo:

Por outro lado, a obra de Thompson sobre paternalismo, cultura plebéia e estilo retórico e ritualístico da justiça na Inglaterra do século XVIII demorou a ser um convite para reproblematizar os "anos populistas". Certamente, são flagrantes as diferenças entre as peculiaridades da sociedade inglesa dos setecentos e as condições históricas do populismo brasileiro. Porém, alguns princípios gerais da noção de hegemonia utilizada por Thompson permitem perceber como os trabalhadores retiravam da ideologia formal do "modelo paternalista" os recursos necessários às suas demandas e lutas, utilizando-o como algo que pertencia ao seu patrimônio adquirido. Se tal modelo era mais generalizante, a apropriação que dele era feita pelos "de baixo" tinha um caráter seletivo, aproveitando noções de justiça social e re-significandoas conforme suas experiências e expectativas.

o conceito de hegemonia tem permeado a maioria das análises sobre o populismo, mas trata-se, em geral, de uma "concepção de imposição hegemônica de dominação de classe como imposição absoluta de categorias ou de estruturas de dominação", impedindo os trabalhadores de manifestarem idéias e ações que não congruentes com os termos dominantes. Pensar o populismo como uma relação de hegemonia significa, ao contrário, considerar as ambigüidades que the eram constitutivas como "um campo de força comum" no interior do qual os diferentes atores sociais "estavam aprisionados". (SILVA; COSTA, 2001, p. 224-225).

Por sua vez, Adriano Duarte e Paulo Fontes defendem uma interpretação interessante acerca do conceito de populismo:

[...] ao invés de tomá-lo como um fenômeno imposto de fora para dentro da classe, ou como uma ideologia que implicaria a manipulação externa, ambos modos insatisfatórios de operar com conceitos históricos, parece adequado compreendê-lo como um sistema político. Ou seja, uma conjugação complexa e sofisticada de interesses e disputas entre atores desiguais, mas que não prescindia da reciprocidade e da negociação, na qual as classes populares estiveram presentes de forma decisiva. (DUARTE; FONTES, 2004, p. 111-112). 
Sem dúvida, as propostas apresentadas, de viés thompsoniano, abrem um novo horizonte para o debate acerca do populismo, destacando-se três pontos:

a) A interpretação do populismo como uma ênfase no protagonismo popular.

b) A compreensão do populismo como um sistema político, em que há disputas, negociações e reciprocidade entre as diferentes classes ou atores sociais. Dessa forma, não há apenas um "jogo político" de manipulação, imposto de cima para baixo, mas um “jogo político” de mãodupla.

c) A utilização do conceito de hegemonia não como a imposição de uma classe sobre as outras, mas o modo como determinados valores das classes dominantes eram selecionados, apropriados e ressignificados pelos "de baixo".

Além da operacionalização do conceito de populismo pelo viés thompsoniano, outra possibilidade de utilização do conceito seria por meio das propostas do intelectual argentino Ernesto Laclau, cuja influência nos debates sobre o populismo no Brasil ainda são tímidas.

\section{O conceito de populismo de Ernesto Laclau}

Ernesto Laclau é contrário às teses de que o populismo seja uma etapa de um estágio de desenvolvimento econômico, como também é contra a ideia de que o populismo seja um conceito pejorativo, embora também não seja necessariamente positivo. De acordo com Laclau, o populismo não é algo específico de um determinado tipo de regime político ou de uma ideologia:

[...] o populismo é uma categoria ontológica e não ôntica - quer dizer, seu significado não será encontrado em algum conteúdo político ou ideológico que se adentre na descrição das práticas de qualquer grupo particular, mas melhor em um modo particular de articulação de conteúdos sociais, políticas ou ideológicas. (LACLAU, 2009, p. 53).

Em outras palavras, para Laclau (2005, p. 150) “é possível definirmos conceitualmente o populismo não como um tipo de movimento - identificado 
com uma base social especial ou mesmo com uma determinada orientação ideológica -, senão como uma lógica política”.

Ainda segundo o autor, essa lógica política pode operar com bases sociais e orientações ideológicas distintas. Porém, surge em momentos de crise de hegemonia, quando as interpelações populares-democráticas não atendidas são articuladas por alguma classe ou fração de classe contra o bloco de poder dominante, em uma situação de crise desse, criando uma relação de equivalência entre essas demandas diante de um antagonista comum - o bloco de poder dominante.

Daremos um exemplo de uma demanda simples: um grupo de pessoas que vivem em um bairro querem uma linha de transporte que os leve desde seus lugares de residência à área em que a maioria deles trabalha. [...].

[...] Suponhamos que a reivindicação é rejeitada. Dessa decisão derivará indubitavelmente uma situação de frustração social. Porém, se trata somente de uma demanda que não é satisfeita, isso não alterará a situação substancialmente. Em contrapartida, se por algum motivo, a variedade de demandas que não encontram satisfação for muito grande, essa frustração multiplicada desencadeará uma lógica social de um tipo completamente diferente. Por exemplo, se o grupo de pessoas naquela área que viu frustrados suas reivindicações de melhor transporte descobre que seus vizinhos estão igualmente insatisfeitos em suas reivindicações acerca da segurança, serviço de água potável, habitação, escolas, etc..., algum tipo de solidariedade emergirá entre eles: todos compartilham o fato de que suas demandas permanecem insatisfeitas. Isto é, as demandas compartilham uma dimensão negativa mais além da sua natureza diferencial positiva.

Uma situação social em que as demandas tendem a reagrupar-se sobre uma base negativa e na qual todas permanecem insatisfeitas é a primeira precondição - embora não a única - do modo de articulação política a que chamamos populismo. (LACLAU, 2009, p. 55-56, grifo nosso).

Para Laclau, essa situação em que uma pluralidade de demandas não satisfeitas reagrupam-se é denominada de cadeia equivalencial'1. Se o sistema político-institucional atender essas demandas não satisfeitas, os vínculos

\footnotetext{
${ }^{11}$ Nesse sentido, Ernesto Laclau (2009, p. 58) ressalta que: "[...] o importante é compreender que a cadeia equivalencial não tem um caráter anti-institucional: ela subverte o caráter particularista e diferencial das demandas. Não há um curto-circuito na relação entre demandas apresentadas ao 'sistema' e a habilidade deste para enfrentá-las. O que teremos que discutir serão os efeitos desse curto-circuito tanto na natureza das demandas como no sistema concebido como uma totalidade".
} 
equivalenciais se tornaram débeis. Porém, ao contrário, se o sistema políticoinstitucional revela-se incapaz de atender às demandas, implicará na mobilização dos atores políticos e criará as condições para uma ruptura populista.

A ruptura populista se dá ao nível da subjetividade popular, fomentando uma fronteira interna que dividirá o social em dois campos: "o poder e os desamparados - o povo" -, isto é, haverá a dicotomização da sociedade em "um poder que se opõe ao conjunto das demandas que constituem a vontade popular". Portanto, “o populismo não é, em consequência, expressão do atraso ideológico de uma classe dominada, mas, ao contrário, uma expressão do momento em que o poder articulatório desta classe se impõe hegemonicamente sobre o resto da sociedade" (LACLAU, 1979, p. 201).

Contudo, Laclau lembra que não há populismo sem a construção discursiva de um inimigo: o Antigo Regime, as oligarquias, os poderosos, o imperialismo, os imigrantes, etc. Nesse sentido, Francisco Panizza (2009, p. 13) observa que Ernesto Laclau entende o populismo como um discurso anti-statusquo, que simplifica o espaço político mediante a divisão simbólica da sociedade entre "o povo" e os "outros", cujas identidades são construções politicas constituídas simbolicamente. Assim, a noção de "povo soberano" como um ator que mantém uma relação antagônica com a ordem estabelecida é um elemento central do populismo (PANIZZA, 2009, p. 15).

Em suma, para Laclau:

Para começar, somente teremos populismo se há uma série de práticas político-discursivas que constroem um sujeito popular, e a precondição da emergência de tal sujeito é, como já vimos, a construção de uma fronteira lógica interna que divide o social em dois campos. Porém, a lógica desta divisão é ditada, como sabemos, pela criação de uma cadeia equivalencial entre uma série de demandas nas quais o momento equivalencial prevalece sobre a natureza diferencial das demandas. Por último, a cadeia não pode ser o resultado de uma coincidência fortuita pura, melhor, deve ser consolidada através da emergência de um elemento que da coerência à cadeia significando-a como uma totalidade. Este elemento é o que chamamos "significante vazio". (LACLAU, 2009, p. 64). 
Acerca dos "significantes vazios", Laclau diz:

[...] a construção de uma subjetividade popular somente é possível sobre a base da produção discursiva de significantes tendencialmente vazios. A denominada "pobreza" dos símbolos populistas é a condição de sua eficácia política - devido a que sua função é converter uma realidade altamente heterogênea em uma homogeneidade equivalencial, somente podem conseguir este objetivo reduzindo ao mínimo seu conteúdo particular. No limite, este processo alcança um ponto onde a função homogeneizante é desempenhada tão somente por um nome: o nome do líder. (LACLAU, 2009, p. 60).

Lembra-nos Laclau (2009, p. 68) que "nenhum movimento político estará absolutamente isento de se tornar populista porque nenhum está incapacitado para convocar o povo contra o inimigo comum, por meio da construção da fronteira social". Dessa forma, "um movimento ou uma ideologia - ou, para colocar ambos sob um mesmo gênero, um discurso - será mais ou menos populista dependendo do grau em que seus conteúdos são articulados pela lógica equivalencial”.

Francisco Panizza ressalta que:

A afirmação dos populistas de que encarnam a vontade do povo não é precisamente nova ou original. As noções de "povo" e de "soberania popular" são centrais nas narrativas da modernidade política e estão relacionadas com questões chaves sobre o significado da natureza da democracia. Ademais, na política moderna, praticamente todo discurso politico apela ao povo ou diz falar em nome do povo, o que torna impossivel distinguir entre entidades populistas e não populistas. (PANIZZA, 2009, p. 15, grifo nosso).

Portanto, o populismo não implica necessariamente em uma manipulação cínica ou instrumental por parte dos políticos, pois "[...] o populismo não se caracteriza como uma 'constelação fixa', mas sim como um arsenal de ferramentas retóricas ('significantes flutuantes') que podem ter os usos ideológicos mais diversos" (Laclau, 2005, p. 237).

Por fim, Laclau define o populismo não como um movimento político pois não está vinculado a um fenômeno delimitável -, mas como uma lógica social e política, cujos efeitos atravessam uma variedade de fenômenos. 
Portanto, na perspectiva de Laclau, o populismo é um "modo de construir o político".

[...] O populismo faz referência ao questionamento da ordem institucional, através da construção do desamparado como agente social - quer dizer, como um agente que é um outro com respeito à forma em que as coisas estão estabelecidas. Porém, isto é o mesmo que a política. Somente teremos através do gesto que toma o estado de coisas existentes como um sistema e apresenta uma alternativa a ele (ou, pelo contrário, quando defendemos esse sistema contra alternativas potenciais existentes). Esta é a razão pela qual o fim do populismo coincide com o fim da política. Teremos o fim da política quando a comunidade concebida como uma totalidade e as vontades coletivas tornarem-se indistinguíveis uma da outra. (LACLAU, 2009, p. 69).

O viés analítico proposto por Ernesto Laclau nos possibilita ressignificar o conceito de populismo, interpretando-o não mais como uma espécie de anomalia dos regimes democráticos, mas, pelo contrário, como um elemento democrático nos sistemas representativos contemporâneos.

\section{Considerações Finais}

Embora na América Latina e na Europa o conceito de populismo proposto por Ernesto Laclau já venha sendo utilizado pela academia para analisar, por exemplo, a ascensão dos fascismos na Europa ou os governos de centroesquerda na América Latina nos últimos vinte anos, no Brasil, apesar dos debates e das críticas ao conceito, o termo populismo é ainda amplamente utilizado pela imprensa (e também por parte de historiadores, cientistas políticos e sociólogos) com um viés pejorativo, simplificado como sinônimo de demagogia. Assim, o debate político, muitas vezes, acaba gravitando em torno da tentativa simplista de classificar líderes, partidos e discursos políticos como populistas e não populistas (estes geralmente apresentados como defensores das instituições, da democracia, do livre mercado, etc.).

Conforme refletimos ao longo do presente artigo, ao analisar alguns dos principais argumentos que envolvem o debate acerca do populismo, verificamos que o conceito de populismo proposto por Ernesto Laclau apresenta-se como um viés analítico alternativo, que permite operacionalizar o conceito, inclusive o 
ressignificando. Afinal, "o populismo é uma lógica social e política", conforme propôs Laclau. Ou, como observa Francisco Panizza (2009, p. 49), "o populismo não é inimigo da democracia, mas sim um espelho no qual a democracia pode contemplar-se a si mesma, inclusive mostrando todas as suas imperfeições".

\section{Referências}

BATISTELLA, Alessandro. Um conceito em reflexão: o populismo e a sua operacionalidade. Revista Latino-Americana de História, São Leopoldo, v. 1, n. 3, p. 468-484, mar. 2012.

BOBBIO, Norberto; MATTEUCCI, Nicola; PASQUINO, Gianfranco. Dicionário de política. 8. ed. Brasília: UnB, 1995. p. 980-986.

CASTRO, Hebe. História Social. In: CARDOSO, Ciro Flamarion; VAINFAS, Ronaldo (org.). Domínios da História: ensaios de teoria e metodologia. Rio de Janeiro: Campus, 1997. p. 45-60.

COSTA, Emília Viotti da. Experiência versus estruturas. Novas tendências na história do trabalho e da classe trabalhadora na América Latina - o que ganhamos? O que perdemos? História Unisinos, São Leopoldo, número especial, p. 17-51, 2001.

COSTA, Hélio da. Trabalhadores, sindicatos e suas lutas em São Paulo (19431953). In: FORTES, Alexandre; NEGRO, Antonio Luigi; SILVA, Fernando Teixeira da; COSTA, Hélio da; FONTES, Paulo (orgs.). Na luta por direitos: estudos recentes em história social do trabalho. Campinas: Unicamp, 1999. p. 87-121.

DEBERT, Guita Grin. Ideologia e populismo. São Paulo: T. A. Queiroz, 1979.

DUARTE, Adriano; FONTES, Paulo. O populismo visto da periferia: adhemarismo e janismo nos bairros da Moca e São Miguel Paulista, 1947-1953. Caderno AEL, Campinas, v. 11, n. 20/21, p. 87-122, 2004.

FERREIRA, Jorge. Trabalhadores do Brasil: o imaginário popular (1930-1945). Rio de Janeiro: Fundação Getúlio Vargas, 1997. 
FERREIRA, Jorge. O nome e a coisa: o populismo na política brasileira. In: O populismo e sua história: debate e crítica. Rio de Janeiro: Civilização Brasileira, 2001. p. 60-124.

FORTES, Alexandre. Formação de classe e participação política: E. P. Thompson e o populismo. Anos 90, Porto Alegre, v. 17, n. 31, p. 173-195, jul. 2010.

GOMES, Angela de Castro. O populismo e as ciências sociais no Brasil: notas sobre a trajetória de um conceito. In: FERREIRA, Jorge (org.). O populismo e sua história: debate e crítica. Rio de Janeiro: Civilização Brasileira, 2001. p. 17-58.

GOMES, Angela de Castro. Reflexões em torno de populismo e trabalhismo. Varia História, Belo Horizonte, no 28, p. 55-68, dez. 2002.

IANNI, Octavio. O colapso do populismo no Brasil. 5. ed. Rio de Janeiro: Civilização Brasileira, 1994.

IANNI, Octavio. A formação do Estado populista na América Latina. 2. ed. São Paulo: Ática, 1989.

LACLAU, Ernesto. Política e ideologia na teoria marxista: capitalismo, fascismo e populismo. Rio de Janeiro: Paz e Terra, 1979.

LACLAU, Ernesto. La razón populista. Buenos Aires: Fondo de Cultura Económica, 2005.

LACLAU, Ernesto. Populism: ¿qué nos disse el nombre? In: PANIZZA, Francisco (comp.). El populismo como espejo de la democracia. Buenos Aires: Fondo de Cultura Económica, 2009. p. 51-70.

MARTINHO, Francisco Carlos Palomanes. O populismo sindical: um conceito em questão. In: REIS, Elisa; ALMEIDA, Maria Hermínia Tavares de; FRY, Peter (orgs.). Política e cultura: visões do passado e perspectivas contemporâneas. São Paulo: Hucitec, 1996. p. 30-49.

PANIZZA, Francisco. Introducción. In: PANIZZA, Francisco (comp.). El populismo como espejo de la democracia. Buenos Aires: Fondo de Cultura Económica, 2009. p. 9-50.

REIS FILHO, Daniel Aarão. O colapso do colapso do populismo ou a propósito de uma herança maldita. In: FERREIRA, Jorge (org.). O populismo e sua história: debate e crítica. Rio de Janeiro: Civilização Brasileira, 2001. p. 319- 377. 
SILVA, Fernando Teixeira da; COSTA, Hélio da. Trabalhadores urbanos e populismo: um balanço dos estudos recentes. In: FERREIRA, Jorge (org.). O populismo e sua história: debate e crítica. Rio de Janeiro: Civilização Brasileira, 2001. p. 205-272.

THOMPSON, Edward P. A miséria da teoria, ou um planetário de erros: uma crítica ao pensamento de Althusser. Rio de Janeiro: Zahar, 1981.

WEFFORT, Francisco. O populismo na política brasileira. 4. ed. Rio de Janeiro: Paz e Terra, 1989. 